\title{
Late complications of reversed gastric tube oesophagoplasty
}

\author{
AC SiTGES, JM SÁNCHEZ-ORTEGA, AS SITGES
}

From the Department of Surgery, Ciudad Sanitaria "Principes de España," Hospitalet de Llobregat, Barcelona, Spain

ABSTRACT This paper reports two late complications of oesophageal replacement using the reversed gastric tube described by Gavriliu. One patient developed obstruction of the gastric tube and the other a perforation of a diverticulum within the gastric tube, both occurring more than 10 years after the original operation. The occurrence of such complications should be made known to surgeons who are contemplating using this form of oesophageal replacement.

Oesophageal replacement using a reversed gastric tube is generally reserved for patients with oesophageal cancer, who are unlikely to survive long enough to develop late complications. Recently, however, Gavriliu's method has been advocated strongly by paediatric surgeons in the United States for the treatment of benign oesophageal strictures. ${ }^{1-4}$ We believe therefore that it is important to report two late complications which caused considerable difficulties of management more than 10 years after the original operations.

\section{Surgical technique}

The method of oesophageal replacement described by Gavriliu (fig 1$)^{56}$ is performed in two stages. In the interval patients are fed through a catheter passed through the gastric tube and into the stomach remnant.

In the first stage of the operation a long gastric tube is constructed from the greater curvature of the stomach, which is divided between two rows of staples or clamps. The base of the tube is situated at the fundus and the distal end of the tube is turned upwards for anastomosis to the oesophagus in the neck. The right gastroepiploic artery is divided close to the pylorus and the tube receives its blood supply from the left gastric artery, which is preserved. Additional length can be obtained by including the pylorus and the first part of the duodenum in the gastric tube, with antroduodenal anastomosis to

\footnotetext{
Address for reprint requests: Professor A Sitges, Departamento de Cirugia, Ciudad Sanitaria "Príncipes de España," Hospitalet de Llobregat, Barcelona, Spain.
}

Accepted 21 May 1985 restore continuity. The prepared tube is passed through a subcutaneous or retrosternal tunnel to the neck, where it is fixed to the skin of the

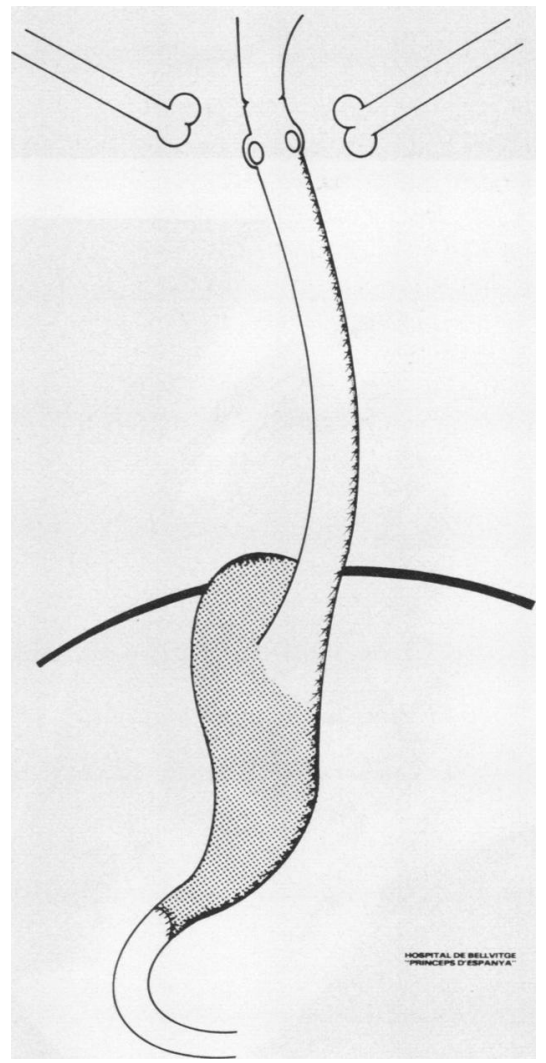

Fig 1 Diagrammatic representation of oesophageal replacement using the reversed gastric tube. 


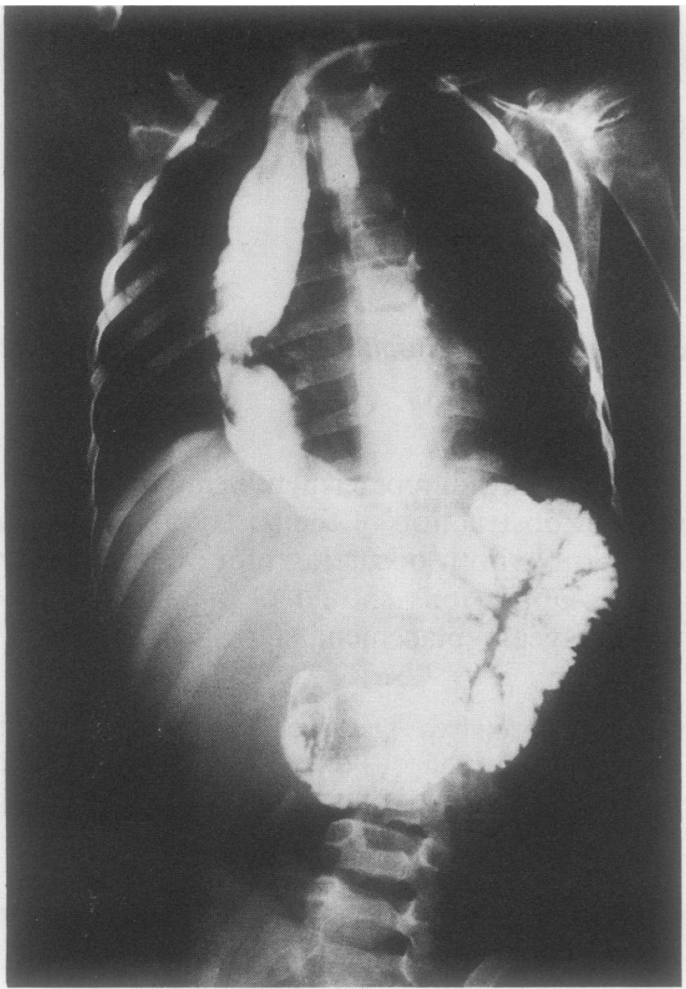

(a)

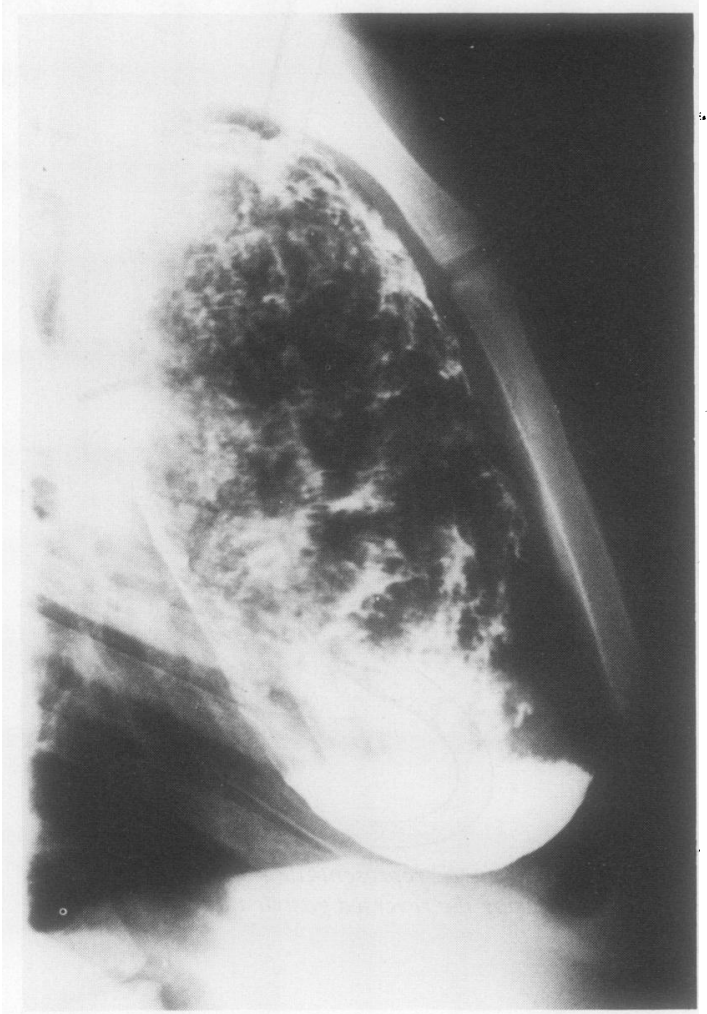

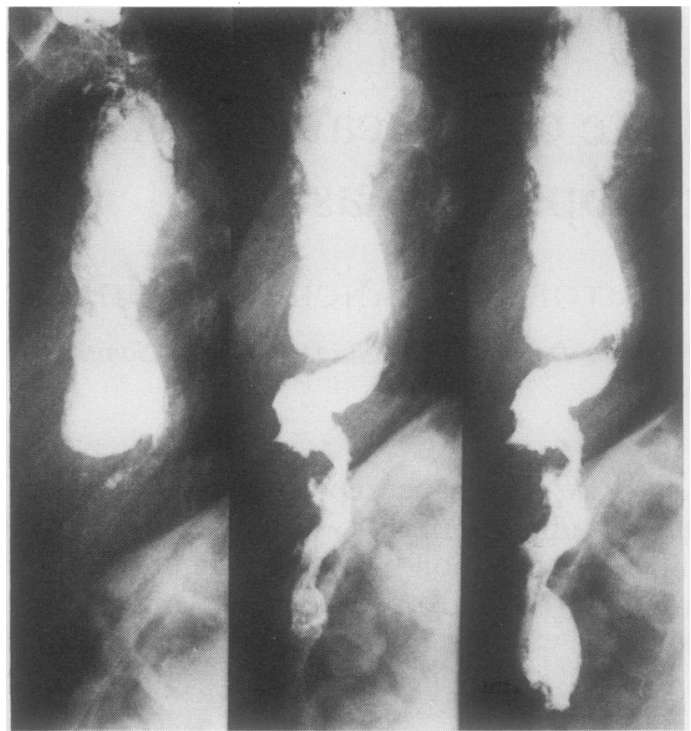

(c)

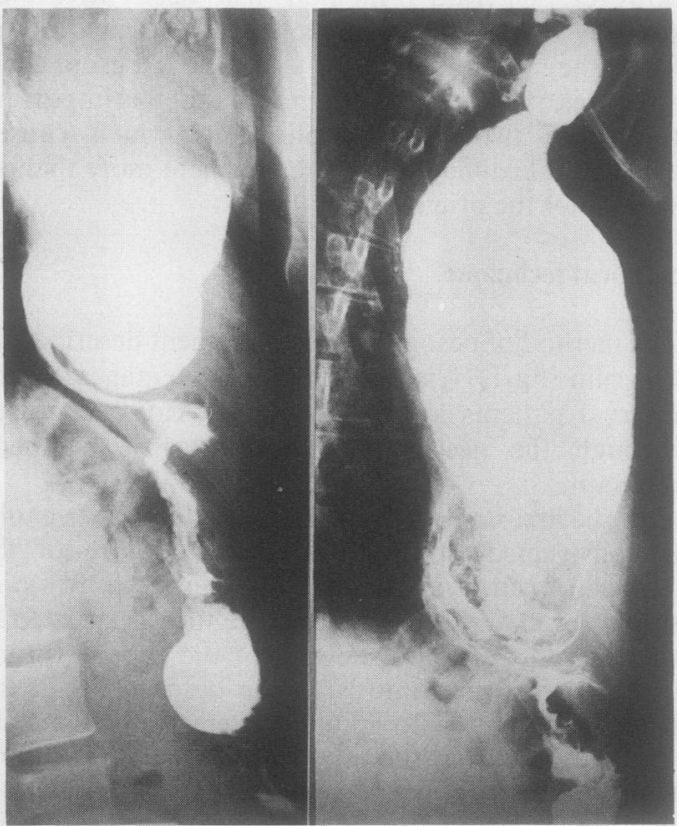

(d)

Fig 2 Patient 1: (a) Barium swallow in 1964 showing the early postoperative appearance; (b) barium swallow in 1977 showing gross distention of the upper part of the tube due to obstruction of the distal segment; (c) barium swallow in 1981 after the second operation; (d) barium swallow in 1984 showing recurrence of obstruction; ( $e$ ) diagrammatic representation of the third operation; $(f)$ barium swallow showing the early appearances after the third operation. 


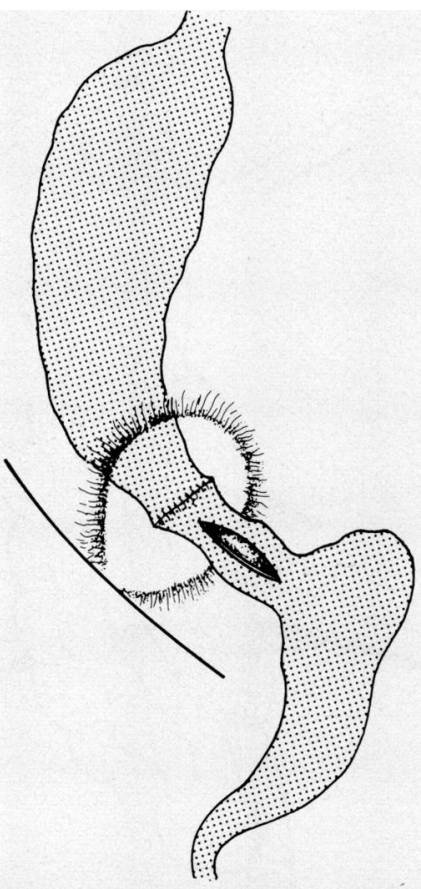

(e)

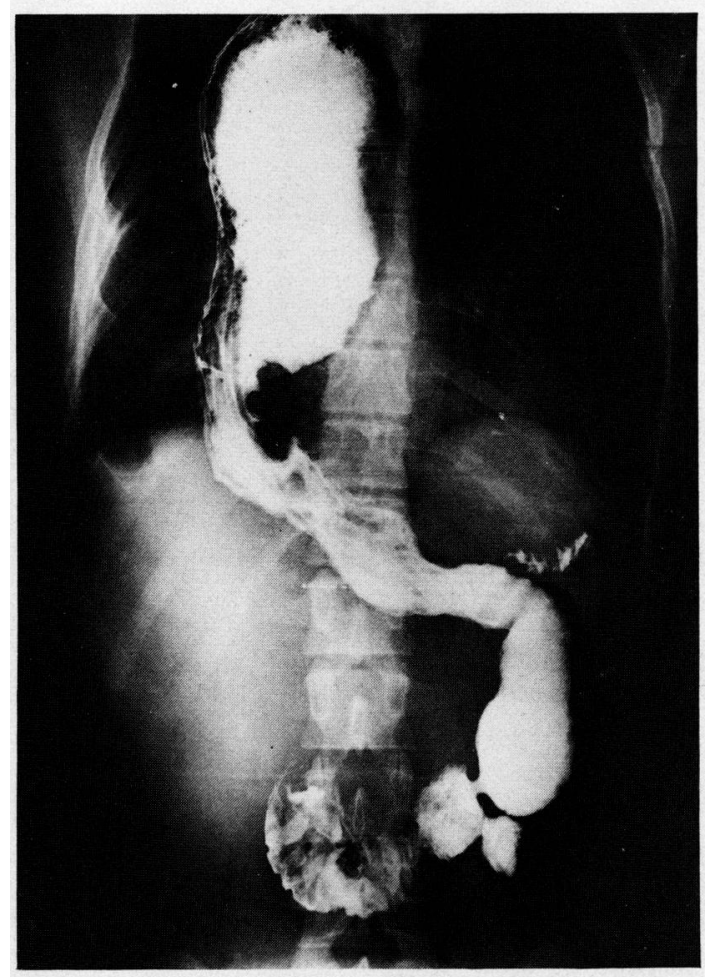

(f) supraclavicular fossa. In the second stage of the procedure the oesophagus is excised and an end to side anastomosis is created between the stump of the oesophagus and the gastric tube in the neck.

\section{Case reports}

\section{CASE 1}

This man was born with a hiatal hernia and developed severe reflux oesophagitis that rapidly caused a long and tight oesophageal stricture. At the age of 2 years he had an abdominal hiatal repair followed two years later by a transthoracic Allison repair. Both operations were unsuccessful, however, owing to severe shortening of the oesophagus. When first referred to us the child could take only semisolid food but he was putting on weight and we decided to postpone operation as long as he remained in a satisfactory nutritional state.

In 1964 at the age of 6 years a retrosternal Gavriliu replacement was performed in two stages according to the method already described, with inclusion of the pylorus in the gastric tube (fig $2 a$ ). His postoperative recovery was uneventful and two years later his growth and nutritional state were normal.

In 1973 a barium swallow showed dilatation of the upper two thirds of the gastric tube but the patient had no symptoms of obstruction. By 1977 he had developed dysphagia for solids and a further barium swallow showed gross dilatation of the upper part of the tube with narrowing just above the diaphragm (fig $2 b$ ). Surgical exploration through the abdomen in May 1977 did not reveal any local cause of obstruction but the adjacent diaphragm was divided and the passage widened. By January 1981, however, dysphagia was almost complete and the patient had lost $10 \mathrm{~kg}$ in weight. Further operation was indicated.

This was performed in November 1981 through a right thoracotomy, which revealed a large gastric pouch that occupied the whole of the anterior mediastinum. The wall of this was $8-10 \mathrm{~mm}$ thick and rigid-apparently because of kinking of the lower segment of the tube by firm adhesion to the sternum. These adhesions were freed and the pouch was then emptied. Longitudinal plication of the pouch was performed to encourage subsequent drainage. The immediate clinical and radiological results were excellent (fig $2 c$ ), but 10 months later dysphagia recurred and by July 1984 the patient was regurgitating after every meal and had again lost weight. A barium swallow (fig $2 d$ ) showed recurrence of the obstruction. A further operation was therefore performed, longitudinal incision and transverse suture of the narrowed area being combined with a longitudinal myotomy of the lower part of the gastric tube (fig $2 e$ ). This has once again produced a good 
short term result and the radiographic appearances are satisfactory (fig $2 f$ ).

\section{CASE 2}

This man was born with a hiatal hernia and gastro-oesophageal reflux. At the age of 11 years he developed an oesophageal stricture, which was treated for 10 years by intermittent dilatation. When referred to us in 1971 he had a columnar lined oesophagus with a very high oesophageal stricture and a mixed type of hiatal hernia. Oesophageal replacement by the Gavriliu technique with inclusion of the pylorus in the gastric tube was performed in April 1972, with oesophageal excision six weeks later. The patient made an uneventful recovery, but two years later barium studies showed a small diverticulum in the gastric tube.

In 1981 the patient presented with sudden retrosternal pain and fever, followed three days later by the appearance of an abscess and fistula in the right anterior chest wall, confirmed by barium studies (fig $3 a$ ).

Surgical treatment of this complex lesion consisted of (1) distal gastrectomy with gastrojejunostomy Roux-en-Y (July 1981); (2) a long segment subcutaneous colon interposition between the oesophageal stump in the neck and the jejunum below the gastrojejunostomy (September 1981 - fig 3b), but

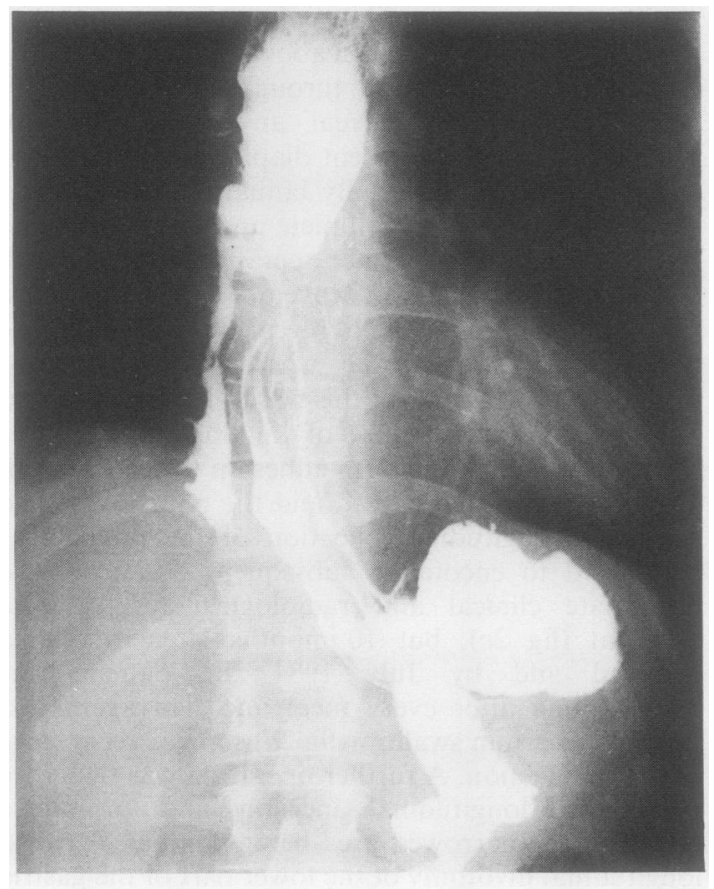

(b)

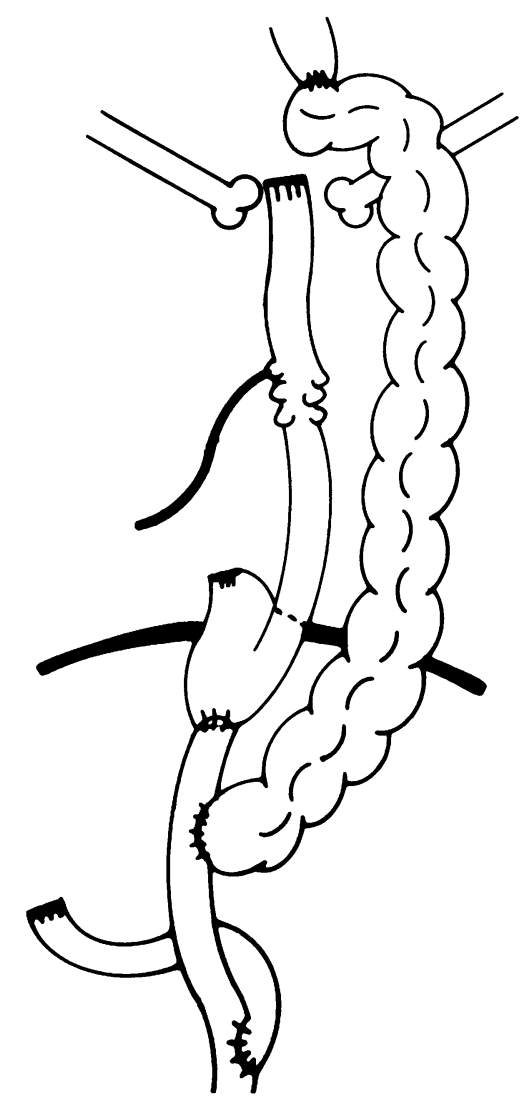

Fig 3 Patient 2: (a) Barium swallow in 1981 showing right lateral diverticulum and fistula; (b) diagrammatic representation of the anatomical arrangement after the second operation.

despite division of the oesophagus the fistula persisted and further surgery was required, comprising (3) transthoracic closure of the fistula with staples and excision of the mucosa of the lower part of the gastric tube (January 1982); and (4) excision of the remaining gastric tube through a cervical approach (October 1982).

When last seen in March 1984 the patient was in good health and swallowing satisfactorily.

\section{Discussion}

In 1975 Gavriliu reported 550 patients with a reversed gastric tube, of whom 11 developed obstruction of the lower segment one to three years after operation. ${ }^{6} \mathrm{He}$ did not find any organic cause to explain this obstruction and thought that the problem was caused by a functional disorder similar to achalasia. The 
patients were therefore treated by a segmental myotomy.

We believe, however, that this was not the mechanism in our first patient. The operative findings suggested that the sequence of events was (1) adhesion of the lower segment of the tube to the sternum; (2) obstruction due to angulation created by the adhesions; and (3) the resulting progressive distention of the gastric tube leading eventually to a large gastric pouch. One possibility is that such adhesions might be the result of leakage from the suture line of the gastric tube; but we had no evidence clinically that this had occurred in the postoperative period.

Gavriliu suggested that the achalasia like appearance of the lower segment of the tube might be caused by friction of the tube against the edges of the new diaphragmatic hiatus. ${ }^{6}$ In our patient, however, section of the diaphragm and enlargement of the hiatus produced no benefit, and we think that the problem was caused by a combination of adhesions and the functional difficulties caused by the antiperistaltic position of the tube.

In the second patient the principal feature was the development of multiple diverticula within the gastric tube. In the alimentary tract in general such diverticula are the result of abnormal motility and we believe this was the explanation in our patient. The long period that elapsed between the operation and the formation of the diverticula suggests a slow process. The fact that diverticula occurred on both sides of the gastric tube excludes the possibility that they were the result of leakage from the suture line, and we again attribute them to the abnormal motility resulting from the antiperistaltic position of the tube.

In conclusion, we believe that the reversed gastric tube may not be a suitable technique for oesophageal replacement in benign strictures of the oesophagus because of the long survival of the patient and the surgical complexities of attempting a further reconstruction.

\section{References}

1 Anderson D, Judson GR. Gastric tube interposition: a satisfactory alternative of the colon for esophageal replacement in children. Ann Thorac Surg 1978; 25:521-5.

2 Heimlich HJ, Wenfield JM. The use of the gastric tube to replace or bypass the esophagus. Surgery 1955; 37:549-53.

3 Heimlich HJ. Reversed gastric tube esophagoplasty for failure of colon, jejunum and prosthetic interpositions. Ann Surg 1975;8:154-60.

4 Sitges-Creus A. Esofagoplastia con tubo gástrico invertido de Gavriliu. Barcelona Quirúrgica 1968; 4:206-8.

5 Gavriliu D. Spasme segmentaire permanent de l'extremité inferiéure du tube gastrique semblable à l'achalasia de l'esophage dans les suites tardives d'une esophagoplastie. Ann Chir Thorac Cardiovasc 1967; 6:234-9.

6 Gavriliu D. Operations for functional obstruction of the cardia. Curr Probl Surg 1975;5:29-34. 